challenge lies in educating maximum employees in shortest time thereby reducing musculoskeletal ailments and promoting safer working by exploring effective communication methods.

Methodolgy A cross-sectional study encompassing Unilever Global Corporate Office Employees' is being undertaken [2013-2017] in India, Dubai(U.A.E), Nairobi (Africa), Durban (South Africa) and South East Asian countries [Philippines, Vietnam, Indonesia, Singapore, Malaysia, Thailand and Sri Lanka] $\mathrm{n}=$ Total 2646 .

Employees were grouped into two, to study following interventions;

- Lecture training including a forty-minute power point presentation \& demonstration on a mock office workstation educating employees on maintaining ideal work postures, back $\&$ eye protection, taking rest breaks, performing desk stretches $\&$ arranging workstations ergonomically to their body dimensions'. $\mathrm{n}=1546$.

- Short demonstrations (ten minutes) on each office floor on a live workstation educating employees on same parameters'. $\mathrm{n}=1100$.

Results Forty minute Lecture training enhances awareness in $>92 \%$ employees'. However, few employees attend this training, due to hectic work schedules.

Short ten minute live demonstrations undertaken in above countries appears to be an excellent tool enhancing awareness in $>90 \%$ employees. When both above interventions were tested for statistical significance, $40 \mathrm{~min}$ lecture was superior only in Indonesia $(\mathrm{p}<0.05)$.

Discussion As few employees attend $40 \mathrm{~min}$ lecture training (though superior) on office ergonomics, the ten minute live demonstration is a promising practical novel intervention as it is comprehensive, undertaken at the workstation, enhancing awareness in maximum employees in a short-time, instilling a feeling of caring and bonding which is vital for a successful and robust office ergonomics control program. A reminder card with tips on chair adjustments, ergonomic arrangement of workstations and a link on desk stretches serves as handy desk-reminder emphasising safer work postures.

\section{REPEATED BACK PAIN AND ROUTES OF EXIT OUT OF PAID EMPLOYMENT AMONG BRITISH CIVIL SERVANTS: A FOLLOW-UP STUDY 1985-2013}

\begin{abstract}
${ }^{1,2} \mathrm{~T}$ Lallukka*, ${ }^{2} \mathrm{M}$ Mänty, ${ }^{3} \mathrm{C}$ Cooper, ${ }^{4} \mathrm{M}$ Fleischmann, ${ }^{5,6,7} \mathrm{~A}$ Kouvonen, ${ }^{4} \mathrm{~J}$ Head, ${ }^{1} \mathrm{JI}$ Halonen. ${ }^{1}$ Finnish Institute of Occupational Health, Helsinki, Finland; ${ }^{2}$ Department of Public Health, University of Helsinki, Helsinki, Finland; ${ }^{3} M R C$ Lifecourse Epidemiology Unit, Universities of Southampton and Oxford, UK; ${ }^{4}$ Institute Department of Epidemiology and Public Health, University College London, London, UK; ${ }^{5}$ Department of Social Research, University of Helsinki, Helsinki, Finland; " 5 SWPS University of Social Sciences and Humanities in Wroclaw, Wroclaw, Poland; 'Administrative Data Research Centre - Northern Ireland, Queen's University Belfast, Belfast, UK
\end{abstract}

\subsection{6/oemed-2018-ICOHabstracts.772}

Introduction Pain is a risk factor for work disability, however, routes of exit out of paid employment among those with chronic pain have not been examined in detail. We aimed to examine the contribution of chronic back pain to subsequent transitions out of paid employment, accounting for covariates. Methods We included participants of the Whitehall II study cohort $(n=8445,69 \%$ men, aged $35-55$ at baseline), with measurements of back pain between phases 1 and 3 (19851994). Exit from paid employment (health-related, retirement not related to health, unemployment, other) was observed between 1995-2013 (phases 4-11). Those remaining in paid employment served as the reference group. Sex, age, parental and own socioeconomic position, job demands, job control, and body mass index were controlled for. Repeated measures logistic regression models were fitted.

Result Altogether 10\% of the participants exited paid employment due to health-related reasons, $2 \%$ due to unemployment and further $6.5 \%$ due to other reasons. After full adjustments, reporting back pain at one time point (26\%) was unassociated with exit due to health reasons, whereas reporting repeated pain $(18 \%)$ was associated with such exit (OR 1.53, 95\% CI: 1.17 to 2.00), when compared to those who did not report pain during phases 1-3 (56\%). Associations were somewhat stronger among middle or lower class employees, and nonexistent among high class employees. Otherwise differences e. g. by age, working conditions or obesity were small. The risk of exit due to other routes than health-related did not vary between participants with or without pain.

Discussion These results highlight the need for early detection of chronic pain to prevent the risk of health-related early exit out of paid employment. The results further emphasise the importance of identification of high risk groups and their modifiable risk factors, such as adverse working conditions

\section{THE TRENDS AND DETERMINANTS OF WORK-RELATED MUSCULOSKELETAL DISORDERS (MSD) IN IRELAND BETWEEN 2002 AND 2013}

Helen Russell*, Bertrand Maitre, Oona Kenny, Dorothy Watson. Economic and Social Research Institute, Dublin, Ireland

\subsection{6/oemed-2018-ICOHabstracts.773}

Introduction In Ireland between 2002-2013, Musculoskeletal Disorders (MSD) accounted for 50\% of self-reported workrelated illnesses. Moreover the average number of days absent (15.9 days) was higher than the average of 12.8 days for all other illnesses (except stress, anxiety and depression).

Methods This paper examines trends and determinants for work-related MSD between 2002 and 2013, using annual cross-sectional data from the Quarterly National Household Survey (QNHS).

Results Rates of MSD were strongly linked to the economic cycle. Rates per 1000 workers ranged from 11 in 2002 to 19 during the economic boom before falling to 7 during the recession (2009). The 2013 rate in a recovering economy was 14 per 1000 workers.

This pro-cyclical pattern remained when characteristics of workers and their workplace were held constant using logistic regression. Furthermore, within sectors, rates were higher when the annual percentage change in employment was positive.

We also found that certain worker and workplace factors influenced the risk of MSD independently. Workers aged 3564 had the highest risk of MSD (2.5 times more than workers $<25$ years). Construction sector workers, followed by those working in agriculture and health, had the greatest risk of MSD. Rates in education and all other services sectors were much lower. The self-employed, those working 40 to 49 hours per week (compared to $<30$ hours), shift workers, and new recruits (with $<6$ months job experience) also had a higher risk of MSD. 